\title{
Spatiotemporal correlation of urban pollutants by long-term measurements on a mobile observation platform
}

\author{
Stefano Crocchianti ${ }^{\mathrm{a}}$, Simone Del Sarto ${ }^{\mathrm{b}}$, Maria Giovanna Ranallic, \\ Beatrice Moroni ${ }^{\mathrm{a}}$, Silvia Castellini ${ }^{\mathrm{a}}$, Chiara Petroselli ${ }^{\mathrm{d}}$, David Cappelletti ${ }^{\mathrm{a}, *}$ \\ ${ }^{a}$ Department of Chemistry, Biology and Biotechnology, University of Perugia, IT-06123 \\ Perugia, Italy \\ ${ }^{b}$ Department of Agricultural, Food and Environmental Sciences, University of Perugia, \\ IT-06123 Perugia, Italy \\ ${ }^{c}$ Department of Political Science, University of Perugia, IT-06123 Perugia, Italy \\ ${ }^{d}$ Faculty of Engineering and Physical Sciences, University of Southampton, 12 University \\ Road, SO17 1BJ Southampton, UK
}

1

\section{Abstract}

We conducted a three-year campaign of atmospheric pollutant measurements exploiting portable instrumentation deployed on a mobile cabin of a public transport system. Size selected particulate matter (PM) and nitrogen monoxide (NO) were measured at high temporal and spatial resolution. The dataset was complemented with measurements of vehicular traffic counts and a comprehensive set of meteorological covariates. Pollutants showed a distinctive spatiotemporal structure in the urban environment. Spatiotemporal autocorrelations were analyzed by a hierarchical spatiotemporal statistical model. Specifically, particles smaller than $1.1 \mu \mathrm{m}$ exhibited a robust temporal autocorrelation with those at the previous hour and tended to accumulate steadily during the week with a maximum on Fridays. The smallest particles (mean diameter $340 \mathrm{~nm}$ ) showed a spatial correlation distance of $\approx 600 \mathrm{~m}$. The spatial correlation distance reduces to $\approx 60 \mathrm{~m}$ for particle diameters larger than $1.1 \mu \mathrm{m}$, which also showed peaks at the stations correlated with the transport system itself. NO showed a temporal correlation comparable

\footnotetext{
${ }^{*}$ Corresponding author

Email address: david.cappelletti@unipg.it (David Cappelletti)
} 
to that of particles of $5.0 \mu \mathrm{m}$ of diameter and a correlating distance of 155 m. The spatial structure of NO correlated with that of the smallest sized particles. A generalized additive mixed model was employed to disentangle the effects of traffic and other covariates on PM concentrations. A reduction of $50 \%$ of the vehicles produces a reduction of the fine particles of $-13 \%$ and of the coarse particle number of $-7.5 \%$. The atmospheric stability was responsible for the most significant effect on fine particle concentration.

\section{keywords}

Cable train measurement platform, Size segregated particulate matter, Nitrogen monoxide, Spatiotemporal structure, Vehicular traffic

\section{Introduction}

Exposure to airborne particulate matter (PM) has been associated with increases in mortality and hospitalizations due to respiratory and cardiovascular disease (Brunekreef and Holgate, 2002, Hoek et al., 2002, Jerrett et al., 2013). A modest increment of $\mathrm{PM}_{2.5}$ (PM whose aerodynamic diameter, $D_{P}$, is less than $2.5 \mu \mathrm{m}$ ), even within concentration ranges well below the present European annual mean limit, has been associated with a significant increase of the relative risk for adverse health outcomes. Also, the health effects were correlated with the vehicular traffic intensity and with the distance of nearest busy roads to the people residence (Raaschou-Nielsen et al. 2013 ).

Urban air pollution shows high variability in space and time which poses significant challenges for accurate exposure assessment and health studies. Indeed, personal exposure is not a static phenomenon but depend both on the spatiotemporal dynamics of air pollution concentrations and individuals' activities (Dias and Tchepel, 2018). Even if clear national guidelines are available to establish how the location of air-quality stations are determined, (Martín et al. 2015) the spatial representativeness of a station does not appear to have a well-established procedure for its assessment . The task is remarkably challenging in the urban environment where chemical reactions and dilution effects can change the spatial extent of impacts from trafficrelated air pollutants (Zhou et al., 2007; Pasquier and André, 2017).

A possible approach to characterise the spatiotemporal structure of urban pollutants is to exploit a dense grid of fixed monitoring stations and land use regression models (see for example Liu et al. (2016)). The spatial domain 
investigated in these approaches is at the urban or more often regional scale and the temporal resolution in the timescale of the day (Kuerban et al. 2020 ).

An alternative approach is the use of mobile platforms. The first tentative, to our knowledge, dates back at least to 1973 when Ott and Eliassen (1973) found that moving a monitoring platform by $200-300 \mathrm{ft}(\approx 60-90 \mathrm{~m})$ could change measured $\mathrm{CO}$ concentrations by a factor of two. In recent years, the use of mobile platforms for urban pollution studies has become a very active area of research. Measurements exploited the use of cars, bus, tram, underground and even bicycles (Westerdahl et al., 2005, Padró-Martínez et al. 2012; van Poppel et al., 2013; Castellini et al., 2014; Hagemann et al., 2014, Pattinson at al. , 2014 Patton et al., 2014; Farrell et al., 2016; Riley et al. 2016; Gozzi et al., 2016; Yu et al., 2016; Li et al., 2018; Rizza et al., 2017; Mitchell et al., 2018). Many significant issues were pointed out in these research works and in particular the importance of the data representativeness (den Bossche et al., 2015) due to the high temporal variability of pollutant concentrations, especially those generated by vehicular traffic. Moreover, technical aspects related to the mobile sampling itself were also addressed (Castellini et al., 2014 Hagemann et al., 2014). In synthesis, the previous works on mobile measurements stressed the need for large datasets and repeated measurements (van Poppel et al., 2013; Peters et al., 2014) and of suitable statistical approaches for data processing (Brantley et al., 2014).

The present project tries to address some of these issues. In particular, the main novelties and strengths of our approach are $(i)$ the duration of the final dataset, based on three years of nearly continuous measurements, (ii) the high temporal and spatial resolutions (tens of seconds equivalent to approx. 50 meters) and (iii) the robustness of the statistical approaches used to interpret the experimental data.

The measurement campaign has been realised by deploying light and portable instrumentations on a cabin of the public transport system Minimetro (MM), operated in the city of Perugia, Italy. MM is an elevated cable train, $3 \mathrm{~km}$-long that crosses a large portion of the urban area of Perugia. It, thus, provides a picture of the spatial and temporal variability of pollutant concentrations for this cross-section of the city. Furthermore, traffic counts were recorded every 5 minutes by sensors put below ground at two main road crossings located below the MM path. The dataset was complemented with measurements carried at two fully equipped air quality station, placed at the side of the MM path. 
The present paper focuses on the spatiotemporal correlation parameters obtained for a relatively stable pollutant, the particulate matter (PM), characterised as a function of the particle size. In addition we present also the case of nitrogen monoxide, NO, a fast reacting species and discuss its spatiotemporal structure in comparison with that of PM. Both pollutants have been characterised continuously, for the entire duration of the project. During the years, we conducted also various short intensive campaigns employing a suite of many portable instrumentations (Castellini et al., 2014, Moroni et al., 2014) which have been not included in the present paper.

Two distinct statistical approaches were applied to the experimental results. Namely, a Hierarchical Spatiotemporal Model (HST) was employed to obtain robust information on the spatial and temporal variability of PM. Furthermore, a Generalized Additive Mixed (GAM) model was used to investigate the influence on PM of covariates such as vehicular traffic, rain, wind, relative humidity and the stability of the planetary boundary layer (PBL).

\section{Material and Methods}

\subsection{Sampling location and Minimetro transport system}

Perugia is a medium-sized city, with a population of approximately 170000 people distributed over an area of about $450 \mathrm{~km}^{2}$. Its historic center is located on the top of a hill at $450 \mathrm{~m}$ a.s.l. while the largest part of its territory is on the southerly flat area $(\approx 270 \mathrm{~m}$ a.s.l. $)$, at the confluence of two large valleys in Umbria, central Italy (figure SM1 of supplementary material). The railway station along with many highly congested roads connecting the center to the suburbs are located at the foot of the hill.

The Minimetro (MM) is an autonomous transport system with unattended train operation opened in 2008. The system consists of 20-25 rubbertired cabins pulled by a cable, a steel rope, driven by an electric engine at the upper end of the rail, where the cars are rotated to travel in the opposite direction. The rail reaches a maximum elevation gradient of $\approx 12 \%$. There are seven stations along the path. When the cabins approach a station, they detach from the rope and travel independently over a system of vertical-axle rubber wheels. Each cabin can accommodate a maximum of 50 passengers and the system at full load can transport 3000 person per hour. The average number of passengers per year is $\approx 3.3 \times 10^{6}$. The cabins travel at a variable speeds between 15 and $25 \mathrm{~km} \mathrm{~h}^{-1}$, depending on the hour of the day. Since the path is three $\mathrm{km}$, the average car frequency is about 2.5 minutes for the 
14 hours of opening (from 7 am to $9 \mathrm{pm}$ ). Half of the pathway is elevated at approximately seven meters above the urban street level. The rest of the pathway includes a first short tunnel $222 \mathrm{~m}$ long, after one-third of the length of the path, and a second tunnel $770 \mathrm{~m}$ long containing the end terminal station. An overview of the MM path is reported in the Supplementary Material (figure SM1 and SM2).

\subsection{Instrumentation set up on the mobile platform}

Thanks to the peculiarity of its design (a relatively constant and low speed, low emissions and the sufficient distance from the road pavement) the Minimetro system is an excellent candidate to serve as a mobile platform for monitoring airborne pollutants without being affected by resuspension phenomena or close direct emission sources. During the 2012-2015 period within the framework of the PMetro project (Castellini et al., 2014) we equipped one of the cabins of MM with an Optical Particle Counter (OPC, Fai Instruments) and basic meteorological sensors (temperature and relative humidity). The OPC was specifically miniaturised for the present experiments starting from the bench version commercialised by FAI. In its development phase the OPC was intercompared with the GRIMM 1.107 and the TSI 3330 optical counters and demonstrated to have comparable performances in terms of sensitivity and response time Castellini et al. (2014). The OPC was set to record every six seconds the particles size distributions in the range $0.28-10$ $\mu \mathrm{m}$ using 22 size bins. Eight of these channels were calibrated by latex spheres. The counter was equipped with a $\mathrm{PM}_{10}$ size-selective inlet, placed on the roof of the cabin, a dilution system, and control of relative humidity in order to avoid multiple counting during peak pollution hours. The typical dilution ratio used was 1:3. All the technical details are reported in Castellini et al. (2014). For a slightly shorter period we installed also a nitrogen monoxide, NO, detector (2B Technology). The NO detector measured concentrations every ten seconds. The cabin motion was controlled with a wireless remote system able to provide in real-time the cabin position along the path. A numerical string identifying the position of the cabin was continuously registered in the data-logger of the OPC. Maintenance and calibration of instruments have been carried out regularly, every few months of operation. During the years we also conducted various intensive campaigns employing a suite of other portable instrumentations (Castellini et al. 2014; Moroni et al., 2014). 


\subsection{Complementary measurements at fixed stations}

The mobile measurements were complemented by fixed monitoring sites placed along the MM path. The first site is the urban background monitoring station of Perugia (AQ1, see figure SM2). AQ1 is located along the MM path, approximately $700 \mathrm{~m}$ from the starting terminal, ST1. This site is equipped with standard instrumentations for meteorological parameters and for gaseous $\left(\mathrm{NOx}, \mathrm{O}_{3}\right)$ and aerosol pollutants $\left(\mathrm{PM}_{10}, \mathrm{PM}_{2.5}\right)$ and was integrated with an atmospheric stability monitor (FAI Instruments) (Perrino et al. 2011). This monitor determines the atmospheric concentration of the short-lived decay products of radon, on hourly sampled $\mathrm{PM}_{10}$ filters. The emanation rate can be assumed to be constant in the urban spatial scale therefore the signal gives information about the dilution properties of the lower boundary layer, the stability of the Planetary Boundary Layer (PBL) and its effects on pollutant concentration. A second air quality station (AQ2), a site exposed mainly to vehicular traffic, is located near the Perugia central railway station. Finally, a bench OPC (FAI Instruments), identical to the one installed on the cabin, was placed outside ST1, 3 meters above the ground, for the full duration of the campaign. In the first year of the campaign this fixed OPC was exploited to test possible particle loss at the inlet of the mobile OPC, due to the cabin motion. Results of the comparison Castellini et al., 2014) indicated a nearly isokinetic regime at the mobile inlet, with a minimal effect of the cabin motion on the particle number measurement. The performances of the OPC's have also been checked by comparison with the gravimetric $\mathrm{PM}_{10}$ and $\mathrm{PM}_{2.5}$ measurements at AQ1 (supplementary material, figure SM3) and against a third bench OPC in the laboratory.

To establish the relationship between the local traffic and the measured concentrations, the total number of vehicles were recorded every $300 \mathrm{~s}$ by an automated set of sensors installed below the road surface, at two main crossroads sites (TRF1 and TRF2), closely located below the elevated MM path.

\subsection{Statistical calculations}

The PMetro project started shortly after the MM line became operational in September 2012 and ended in May 2015. Due to the high time resolution measurements, it collected a large amount of data. The mobile OPC data totaled $\approx 6.1 \times 10^{6}$ counts for each bin, distributed in 671 MS Excel XLS files $(\approx 2.5 \mathrm{GiB})$. After a preliminary description of the whole dataset by standard statistical tools, discussed in Sec. 3.1, we extracted a single, typical 
year for a more detailed statistical analysis. To this aim, we considered data from March 2014 to February 2015 for a total of 238 available days. The typical year has a minimum number of missing data and the best-balanced representation of all the four seasons during the time of the campaign. A discretisation both in time and space was adopted. Specifically, OPC data were spatially aggregated by dividing the Minimetro path into 44 spatial sectors of approximately $50 \mathrm{~m}$ lengths. As far as the temporal aggregation is concerned, data were aggregated by the hour for a total of 14 observations per day. We finally obtained a spatiotemporal grid, composed by 238 (days) $\times 14$ (hours) $\times 44$ (spatial sectors $)=146,608$ points. In each spatiotemporal point, data consisted of PM number concentration divided into 22 bins according to the particle size and NO concentration.

For the spatial and temporal correlation analyses, we used the HST model proposed by Sahu et al. (Sahu et al., 2007), in particular its simplified version contained in the $\mathrm{R}$ package spTimer (Bakar and Sahu, 2015). This model, along with some variations, has been widely applied in the literature to investigate the spatiotemporal features of environmental data (Sahu et al., 2009; Berrocal et al., 2012; Crimp et al., 2015; Del Sarto et al., 2016a b; Lu et al., 2018).

As regards the analyses related to the covariate effects on the concentration of airborne particles, we employed a GAM model (Lin and Zhang, 1999; Ruppert et al., 2003), available in the R package mgcv (Wood, 2017); model fitting was evaluated by using the Bayesian Information Criterion (BIC) (Schwarz, 1978). The BIC is suitable in situations where there is a large sample size with respect to the number of parameters, which is the case in our application.

Given that repeated observations were available within each day, we used a random intercept for the day (Del Sarto et al., 2019). Since we have a clustered structure of the data given by repeated measurements on the same day, we introduce in the model specification cluster-specific (day-specific) random effects that allow us to model sources of unobserved heterogeneity in the data among days which are not captured by the available covariates.

GAM models have been broadly applied to environmental studies, when the classical assumptions of linear regression models (i.e., observation independence and linear covariate effects) did not hold (Clifford et al., 2011, Kloog et al., 2015; von Brömssen et al., 2018; Zhang et al., 2018; Virgilio et al. 2018). In this regard, in order to exploit all the available data sources (OPC, meteorological and traffic counts), data were spatially restricted to 
those spatial sectors where the Minimetro elevated path intersected the two road crossings (TRF1 and TRF2) for which vehicular traffic counts were also available. Moreover, in order to retain more information on vehicular traffic, data were temporally aggregated by half-hour (rather than by hour). Finally, as regards the meteorological conditions, since they were collected every hour by the fixed monitoring stations, observations at the half-hour were obtained as the average between two consecutive hourly observations.

\section{Results and discussion}

\subsection{Particulate matter phenomenology in the Perugia urban environment}

The mean meteorological and air quality parameters measured at AQ1 and AQ2 stations for the entire measurement period (2012-2015) and for the typical-year analysis are reported in Table 1. AQ1 is placed near the MM station ST2 (see figure SM2), after the access road to the MM parking lot. AQ2 is located at the MM station ST4, in a more traffic congested sector of the city. The $\mathrm{PM}_{10}$ and $\mathrm{PM}_{2.5}$ concentrations measured at AQ1 and AQ2, once averaged for the full period, were similar. On the other side, AQ2 recorded higher values for $\mathrm{NO}, \mathrm{NO}_{2} / \mathrm{NOx}$ ratios and consistently lower values of $\mathrm{O}_{3}$, a typical behaviour of a vehicular traffic site. The parameters for the typical year were consistent with the 3 years averaged values. The traffic counts at two crossroads sites (TRF1 and TRF2) were recorded for the full period of measurements. The average number of vehicles per day at TRF1 and TRF2 was of the order of 22000 and 40000, respectively (see supplementary material, figures SM4, SM5).

The mobile platform allowed to record a highly space-resolved $(\approx 50$ m) cross-section of the pollutants' concentrations, roughly every 25 minutes. The average volume distribution of particulate matter recorded by the OPC installed in the mobile platform averaged for the entire 3-year period is plotted in figure 1 as a function of the geometric mean diameter $D_{P}$. The figure shows the typical structure of an aerosol volume distribution with a broad minimum around $0.8 \mu \mathrm{m}$, separating fine and coarse fractions of the atmospheric aerosol. Moreover, a broad maximum located at around $4 \mu \mathrm{m}$, individuates the coarse fraction. Two finer features can be noticed in the volume distribution respectively at 0.54 and $2.75 \mu \mathrm{m}$. A test bench in the lab with a reference OPC suggested the first maxima at $0.54 \mu \mathrm{m}$ is an artifact related to the instrument design of the optical particle counter. On the other side, the maximum at $2.75 \mu \mathrm{m}$ was proven to be a peculiar fingerprint of the 
MM transport system, related to the brake system of the MM cabins, to be discussed below.

Some differences in the volume distribution emerged when seasonally averaged data are considered (open symbols in figure 1). Fine particles prevail in the wintertime while the coarse fraction in the summertime, especially for $D_{P}>4 \mu \mathrm{m}$. When considering measurements taken with the fixed OPC, located at the beginning of the MM path (ST1), this seasonal trend was not present (see supplementary material, figure SM5), which is not surprising considering that ST1 is located in the main parking lot of the MM transport system. Therefore, the mobile measurements were able to pinpoint a seasonal effect on the aerosol volume distribution which was evident only when a large section of the city was monitored.

The particle volume distribution was not homogeneous in the city, even when averaged for 3 years. The minimum concentration for each size bin were recorded inside the tunnels for all the classes. To better visualise how the concentrations change along the MM path, the 22 size bins were summed into two fractions: fine particles, with $D_{P}<1.1 \mu \mathrm{m}$, and coarse particles, with $D_{P} \geq 1.1 \mu \mathrm{m}$. The timeline of fine and coarse particle concentrations for the three years campaign is shown in figure 2. Concentrations are plotted as weakly averages. The trend of fine particles shows the typical high-winter and low-summer alternation. By contrast, the coarse particles are more uniform during the years, apart for weeks of a much higher concentration, above the $90^{\text {th }}$ percentile of the dataset, indicated with a dashed line in figure. For almost all the cases, the sharp increases of coarse particles coincided with periods of intense Saharian dust intrusions, as registered at the regional background site of Monte Martano (Moroni et al., 2015; Federici et al. (2018) and confirmed by back-trajectories calculations of air masses provenance (Petroselli et al., 2018). Interestingly during the dusty days, the mobile measurements showed a patchy distribution of PM all along the transect, with peaks coinciding with intersection with the heavy traffic roads. This fact suggests the resuspension of Saharan dust from roads by vehicular traffic as affecting urban air quality for days during/after the events. Some examples of dusty and non-dusty days are reported in supplementary material (figure SM7).

The fine and coarse particles and the NO concentrations are reported in figure 3 as a function of the linear distance from the starting terminal station. and the associated standard deviations are very small Neither the two PM fraction nor NO concentrations are constant as a function of the 
distance and both show a distinctive structure in the urban environment. The data are averaged over the entire measurement period and the relative standard errors associated with the mean values are smaller than $1 \%$. The fine particles concentration exhibits a broad oscillating behaviour with maxima corresponding to crosses of the MM path with the main roads of the city and an overall decrease trend in the last part of the MM path, probably connected to the variation of the elevation and the presence of the terminal tunnel. NO shows a minimum concentration in the urban park and a broad maximum in the main traffic area, followed by a decreasing trend in the last part of the MM path, similar to that of fine PM. By contrast, the coarse fraction presents distinct maxima in correspondence with to the Minimetro stations, even inside the tunnel. Tunnels are used only by the MM cabins and appear very effective in reducing fine particle and NO concentrations, particularly the last and longer one. Analogous plots for the separate bins (supplementary material, figure SM8) indicate that the structure of the fine fraction is common to the first six size bins. Then, gradually, the oscillations smooth down and starting from $D_{P} \geq 1.6 \mu \mathrm{m}$ the maxima of coarse particles at the stations prevail. The results can be rationalised as the predominance of different sources within each size bin. In particular, the cabins of MM when arriving at the stations are a source of coarse particles. Here, the friction of the horizontal rubber-tired wheels used to stop and accelerate the cabins has been proven to produce a considerable amount of metal-bearing and halogen-bearing particulate matter. We made such identification by individual particle characterisation carried out using the Scanning Electron Microscope (SEM) Energy Dispersive X-ray Spectroscopy, which revealed fine metal particles stuck on larger rubber particle (Moroni et al., 2014). This source is necessarily composed of fresh particles mixed by resuspended ones, particularly inside the longer tunnel where they tend to accumulate. Therefore, SEM results allowed to identify the particles responsible for the maximum observed in the size distribution at $2.75 \mu \mathrm{m}$ (see above and figure 1) which are also responsible for the maxima of coarse particle numbers observed at the stations (figure 3). Exposure to airborne particulate matter in subway systems is of great concern (see (Martins et al., 2016) and references therein) and depends on ventilation conditions, length of tunnels, wheels and rail-track materials and breaking mechanisms among other factors (Moreno et al., 2015, Martins et al., 2015). The nature of pollutants inside a tunnel can be very variable and undoubtedly different from the outdoor. As discussed above, this is the case of the present MM transport systems, 
which besides being, in general, a clean transport system, generates a specific aerosol produced by the braking system and erosion of the tires.

\subsection{Spatiotemporal correlations of particulate matter}

In order to draw a quantitative description of the spatial and temporal correlations of pollutants and to evaluate the relative significance of the parameters influencing their concentrations, we applied two different statistical approaches.

The first step of the statistical analysis considered an HST model, in which each one of the 22 bins was considered as a separate response variable. As a consequence, 22 different spatiotemporal models were estimated. Furthermore, no covariates were considered at this phase of the analysis. This approach allowed us to determine both the temporal and spatial correlation as a function of the size bin. The results are shown in figure 4 .

In particular, the temporal autocorrelation parameter (denoted by $\rho$ ) represents the correlation of an observation collected at a particular hour of a specific day to that at the previous hour of the same day, and is plotted in the upper panel of figure 4. Fine particles exhibit a strong temporal correlation with those at the previous hour ( $\rho$ values close to 1 ). The correlation is quickly lost as the particle dimension increases. The results are in good agreement with those discussed in the previous section (see figure 3) and in particular with the accumulation of coarse particles in a distance range of \pm $50 \mathrm{~m}$ at the stations.

The spatial correlation parameter, on the other hand, provides information on the (maximum) spatial distance at which measures of particles remain correlated. The lower panel of figure 4 illustrates the spatial correlation distance, expressed in meters, as a function of the particle diameter, $D_{P}$. Strikingly, the smallest particles showed a spatial correlation that persists up to $\approx 600 \mathrm{~m}$. The correlation drops down swiftly for larger diameters reaching a constant value of $60 \mathrm{~m}$ above $\approx 1.1 \mu \mathrm{m}$. This spatial correlation length is very similar to the amplitude of local maxima presented by the coarse fraction represented in figure 3. These results can be interpreted in terms of a size-dependent deposition dynamics that confers to the coarse particle a sharper spatial distribution near the sources. Even if approximated estimates of spatial extent of impact of urban pollutants are available in the literature (Zhou et al., 2007; Pasquier and André, 2017) this is the first time that size resolved information are obtained for PM. 
A further element in this interpretation is represented by the corresponding temporal and spatial correlation for nitrogen monoxide. $\rho_{N O}$ resulted to be 0.263 , comparable to the particles of $D_{P}=5.0 \mu \mathrm{m}$, and its correlating distance $155 \mathrm{~m}$. The two parameters suggest a short lifetime of the gaseous species combined to certain mobility, which has to be related to the NO reactivity. The NO concentration has been correlated to that of the size selected PM considering the data averaged along the MM path. Correlation coefficients, plotted in the lower panel of figure 5 , are higher for the smallest particle sizes with values that drop below zero for the coarser particles. For the smaller size fraction $\left(D_{P}=0.34 \mu \mathrm{m}\right)$, the correlation coefficient was relatively constant along the MM path, as shown in the upper panel of the same figure. These results are consistent with those reported by Padró-Martínez et al. (2012) obtained with a mobile platform equipped with fast-response instruments for monitoring gas- and particle-phase pollutants. These authors found a better correlation of $\mathrm{NO}$ with ultrafine particles than with $\mathrm{PM}_{2.5}$ and even less with $\mathrm{PM}_{10}$.

\subsection{Effect of environmental and meteorological covariates}

To quantify the role played by the different meteorological and environmental variables and according to our previous results (Ranalli et al., 2016), we grouped the 22 bins into four different size fractions $\left(0.28 \leq D_{P}<0.60\right.$ $\left.\mu \mathrm{m}, 0.60 \leq D_{P}<1.10 \mu \mathrm{m}, 1.10 \leq D_{P}<3.00 \mu \mathrm{m}, D_{P}>3.00 \mu \mathrm{m}\right)$. Particles with diameters larger than $5.5 \mu \mathrm{m}$ were not considered for this analysis because their distribution was heavily zero-inflated and the assumption of normality for the response variable would be violated even after transformation.

We added several covariates to the above spatiotemporal models, such as:

- temperature and relative humidity (both measured along the path), radon concentration and atmospheric pressure (measured by a fixed monitoring station), precipitation and wind speed.

- characteristics of the spatial bin (presence of tunnels, urban parks, car parking, Minimetro stations)

- day of the week, hour of the day, major public events, days of Saharan dust intrusions.

The complete results of the model, including the estimated coefficients, are reported in supplementary material Table SM1. 
An interesting effect obtained with this analysis is the dependence of pollutants concentration on the day of the week. Results, obtained for the smallest size fraction $(0.28-0.60 \mu \mathrm{m})$, for the coarse particles $\left(D_{P} \geq 1.1\right.$ $\mu \mathrm{m})$, and NO are reported in Table 2. As we can see, the model estimates are all significantly different from 0 and suggest an accumulation of fine particles and NO during the week, with a maximum on Friday and with a decline during the weekends. The weekends decline was observed for NO and particle concentration also by other experiments with a mobile platform Padró-Martínez et al. (2012). This result confirms the accumulation effect during the weekdays and also indicates the underlying action of traffic as one of the driving factors of the observed phenomenon. Indeed, the city of Perugia, is characterized by a rather periodic behavior of the vehicular traffic (see supplementary material, figures SM4 and SM5), distinguished by relatively constant values from Monday to Friday, a decrease of about $10 \%$ on Saturdays and a more substantial reduction of $\sim 30 \%$ on Sundays.

In Table 2 we reported the effects related to the presence of tunnels, urban park and stations, as well as those related to temperature and relative humidity. The tunnel has a negative effect on NO and fine particles concentrations, acting as a shield from these outdoor pollutants. The overall effect of the tunnel on coarse particles is negligible, due to a compensation between the shield effect and the indoor coarse particle source, discusse above. The urban park has a depressing effect on NO concentration (see also Figure 3 and Table 1).

The statistical spatio-temporal model allowed us to understand many interesting urban pollution dynamics. For example, the case of the two major public events in Perugia, the Eurochocolate and Umbria Jazz international festivals, both lasting two full weeks with thousands of foreigner visitors in the city, was explicitly considered in the model. As a result (see Table SM1 of Supplementary Material for details) the particle number concentration was lower than other periods of the year; this pattern was the same for all the four-dimensional classes and probably related to the strict management of vehicular traffic. Indeed, during the events the access to the city center was forbidden for private cars. Most of the vehicles were confined in parking lots at the borders of the city and visitors transported in the city center by public transport means.

As expected, we observed higher particle number concentrations in all the four classes during the Saharan dust advections. This effect is particularly high for larger particles since coarser particles mainly compose Saharan dust. 
Indeed, the contribution of long-range transported aerosol on the particulate matter can vary substantially due to the source area but also to the synoptic and mesoscale meteorology, and the local wind conditions. Estimating longrange contribution to the particulate is essential to plan effective measures aiming to reduce population exposure to such pollutants.

In the second step of the analysis, we examined the effect of various factors on the concentration of airborne particles and to identify their contribution. Vehicular traffic data were restricted to those sectors where the traffic information was available. Several GAM models were fitted to the dataset, each time using a different size bin as response variable (for a total of 16 models) and taking into account the following covariates: temperature (spline), wind speed, relative humidity, atmospheric pressure, total solar radiation (log-transformed), radon concentration (log), rainfall and vehicular traffic $(\log )$.

Determining the effect of vehicular traffic on the particle concentration required an intensive model selection step. In essence, given the $300 \mathrm{~s}$ temporal resolution of the traffic dataset, it was first of all necessary to find out the covariate that best represented the vehicular traffic, taking into account also the cumulative sum of vehicles (log-transformed) passed earlier to the current time point. In particular, for each diameter bin (i.e., for each response variable), several models were estimated, each one with a different traffic-related covariate (other things being unchanged). This variable was obtained by cumulating the vehicles passed $H$ hours before the current time point, where $H$ ranged from 0.5 (previous half-hour) to 24 (previous day). The model fitting was evaluated using the BIC, and the model with the lowest BIC was retained. As a consequence, this procedure allowed for the selection of the best traffic-related covariate for each fraction. Results are reported in figure 6, showing, for each size bin, the regression coefficient estimates along with the $95 \%$ confidence intervals. Each confidence bar was color-coded according to the best traffic-related covariate expressed in terms of the number of previous hours for cumulating the vehicles. It turned out there was not a unique value for $H$ along with the bins, but it varied from 2 to 5 hours. At the same time, the effect of traffic on the particle number plotted on the $y$-axis, varied from 0.15 to slightly above 0.25 . The latter parameter represents the percent variation of the particle numbers for a corresponding increase of $1 \%$ in the number of vehicles.

Specifically, particles with a size smaller than $0.7 \mu \mathrm{m}$ showed a similar effect of traffic on the number concentration with a coefficient estimates of 
around 0.26 . This means that a decrease of $10 \%$ of the number of vehicles would lead to a reduction of around $2.6 \%$ of fine particle number. The best traffic-related covariate resulted in being the cumulative sum of vehicles in the previous 4 hours, except for the smallest size class (first bin) having 5 hours. The four or five cumulation hours needed to better trace the vehicular effect on smaller particles seemed to indicate the mobility of the particles as the critical factor explaining the large oscillation of fine fraction along the path, rather than the heterogeneity of the sources distribution within the city area.

On the other side there was a clear reduction of both the traffic effect on the particle number and the value of $H$, as $D_{P}$ increase. The transition from high to low correlation occurred in the size range were the observed aerosol size distribution showed the transition between fine and coarse particles. The trend levelled for $D_{P}>1.6 \mu \mathrm{m}$. Particles larger than $1.6 \mu \mathrm{m}$ exhibited a constant response to traffic with a coefficient estimates of around 0.16. This means that a decrease of $10 \%$ of the number of vehicles would lead to a reduction of around $1.6 \%$ of coarse particle number. The constant correlation of heavier particles might also reflect the traffic resuspension activity.

The role of some meteorological covariates on PM concentration is shown in figure 7 . In particular, the effect $1 \%$ variation of radon concentration is considered together with the effect of a variation of one unit of $\mathrm{RH}$, wind speed, and rain. The radon concentration is a proxy of the atmospheric stability and has a maximum effect on the smaller particles. Specifically, a $10 \%$ increase in the radon concentration was associated with a $6 \%$ increase in the fine particle concentration. The effect rapidly decreased and leveled off for particles with diameters larger than $1.1 \mu \mathrm{m}$. Atmospheric stability is still affecting the concentration of the coarse particles but only to half of the fine particles. Rain, as expected, has a depletion effect both on fine and coarse particles, while RH stimulates an apparent increase of the number of fine particles, due probably to the growth of smaller ultrafine aerosols, even if this effect was relatively small. Finally, an increase in wind speed resulted in a decrease of fine particles, while its effect is not statistically significant for particles with a diameter larger than $1.1 \mu \mathrm{m}$.

\section{Conclusions}

Spatiotemporal correlations of urban particulate matter have been investigated with a mobile observation platform, operated continuously for three 
years in the city of Perugia. High-resolution measurements (10 sec. corresponding to $50 \mathrm{~m}$ ) produced a huge dataset interpreted with a hierarchical spatiotemporal and generalized additive mixed models. We found that fine aerosol particles exhibit a robust temporal correlation with those at the previous hour, are generated by 4 hours cumulated vehicular traffic, are spatially correlated for $\approx 600 \mathrm{~m}$ and tended to accumulate steadily during the week with a maximum on Fridays. The size dependence of the spatiotemporal correlation has been characterised in the in the 0.28-10 $\mu \mathrm{m}$ range. Nitrogen monoxide, NO, showed a spatial and temporal resolution that matched that of larger aerosol particles. A reduction of $50 \%$ of the vehicles produces a reduction, $-13 \%$ of the fine particles and $-7.5 \%$ of the coarse particle number. The role of meteorological covariates was assessed by a GAM model and atmospheric stability was responsible for the most significant effect on fine particle concentration. An increased use of public transportation in the context of the major popular events in the city effectively lowered particulate matter concentration. Saharan dust advections produced an evident effect on particle size distribution due to resuspension of coarse particles in all the urban transect; the effect was attributed to traffic and lasted one week for the significant intrusion events. The results of present work could provide relevant information for urban pollution control.

\section{5. acknowledgement}

We thank MIUR and the Università degli Studi di Perugia for financial support to the project AMIS and to project LEPA, through the program "Dipartimenti di Eccellenza (2018-2022)". We are indebted with people at FAI Instruments which supported with eagerness and friendships the project for the three years of campaign. Comune di Perugia, ARPA Umbria and Leitner spa are also acknowledged for supporting the experimental campaign. We gratefully thank the three anonymous Referees for the constructive comments and recommendations which definitely helped to improve the readability and quality of the paper.

\section{Author contributions}

Conceptualization, D.C.; methodology, M.G.R. and D.C.; investigation, C.P., B.M., S.C., S.C., S.D.S. and D.C.; data curation, S.C., S.C. and S.D.S; statistical modeling M.G.R and S.D.S.; writing-original draft preparation, 
565 S.C., D.C.; writing-review and editing, C.P., S.C., M.G.R., B.M., S.D.S., 566 and D.C.; Supervision, D.C.; Project administration, D.C.; Funding acquisi567 tion, D.C. All authors have read and agreed to the published version of the 568 manuscript. 
Bakar, K. S., Sahu, S. K., 2015. sptimer: Spatio-temporal bayesian modelling using r. J. Stat. Soft. 63, 1-32.

Berrocal, V. J., Gelfand, A. E., Holland, D. M., 2012. Space-time data fusion under error in computer model output: an application to modeling air quality. Biometr. 68, 837-848.

Brantley, H., Hagler, G., Kimbrough, E., Williams, R., Mukerjee, S., Neas, L., 2014. Mobile air monitoring data-processing strategies and effects on spatial air pollution trends. Atmos. Meas. Tech. 7, 2169-2183.

Brunekreef, B., Holgate, S., 2002. Air pollution and health. The Lancet 360, 1233-1242.

Castellini, S., Moroni, B., Cappelletti, D., 2014. Pmetro: Measurement of urban aerosols on a mobile platform. Measur. 49, 99-109.

Clifford, S., Low Choy, S., Hussein, T., Mengersen, K., Morawska, L., 2011. Using the generalised additive model to model the particle number count of ultrafine particles. Atmos. Environ. 45, 5934-5945.

Crimp, S., Bakar, K. S., Kokic, P., Jin, H., Nicholls, N., Howden, M., 2015. Bayesian space-time model to analyse frost risk for agriculture in southeast australia. Int. J. Climat. 35, 2092-2108.

Del Sarto, S., Marino, M. F., Ranalli, M. G., Salvati, N., 2019. Using finite mixtures of $\mathrm{m}$-quantile regression models to handle unobserved heterogeneity in assessing the effect of meteorology and traffic on air quality. Stoc. Environ. Res. Risk Assess. 33, 1345-1359.

Del Sarto, S., Ranalli, M. G., Bakar, K. S., Cappelletti, D., Moroni, B., Crocchianti, S., Castellini, S., Spataro, F., Esposito, G., Ianniello, A., Salvatori, R., 2016a. Bayesian spatiotemporal modeling of urban air pollution dynamics. In: Di Battista, T., Moreno, E., Racugno, W. (Eds.), Topics on Methodological and Applied Statistical Inference. Springer International Publishing, pp. 95-103.

Del Sarto, S., Ranalli, M. G., Cappelletti, D., Moroni, B., Crocchianti, S., Castellini, S., 2016b. Modelling spatio-temporal air pollution data from a mobile monitoring. J. Stat. Comp. Simul. 86, 2546-2559. 
den Bossche, J. V., Peters, J., Verwaeren, J., Botteldooren, D., Theunis, J., Baets, B. D., 2015. Mobile monitoring for mapping spatial variation in urban air quality: Development and validation of a methodology based on an extensive dataset. Atmos. Environ. 105, 148 - 161.

Dias, D., Tchepel, O., 2018. Spatial and temporal dynamics in air pollution exposure assessment. Int. J. Environ. Res. Public Health 15, 558.

Farrell, W., Weichenthal, S., Goldberg, M., Valois, M.-F., Shekarrizfard, M., Hatzopoulou, M., 2016. Near roadway air pollution across a spatially extensive road and cycling network, Environ.Poll., 212, 498-507.

Federici, E., Petroselli, C., Montalbani, E., Casagrande, C., Ceci, E., Moroni, B., Porta, G. L., Castellini, S., Selvaggi, R., Sebastiani, B., Crocchianti, S., Gandolfi, I., Franzetti, A., Cappelletti, D., 2018. Airborne bacteria and persistent organic pollutants associated with an intense saharan dust event in the central mediterranean. Sci.Tot. Environ. 645, 410-410.

Gozzi, F., Della Ventura, G., Marcelli, A. 2016. Mobile monitoring of particulate matter: State of art and perspectives. Atmos. Poll. Res. 7, $228-$ 234.

Hagemann, R., Corsmeier, U., Kottmeier, C., Rinke, R., Wieser, A., Vogel, B., 2014. Spatial variability of particle number concentrations and nox in the karlsruhe (germany) area obtained with the mobile laboratory aerotram. Atmos. Environ. 94, $341-352$.

Hoek, G., Brunekreef, B., Goldbohm, S., Fischer, P., van den Brandt, P., 2002. Association between mortality and indicators of traffic-related air pollution in the netherlands: a cohort study. The Lancet 360, 1203-1209.

Jerrett, M., Burnett, R., Turner, B. B. M., Krewski, D., Martin, G. T. R., van Donkelaar, A., Shi, E. H. Y., Gapstur, S., Thun, M., Pope, C. I., 2013. Spatial analysis of air pollution and mortality in california. Am. J. Respir. Crit. Care. Med. 188, 593-599.

Kuerban, M., Waili, Y., Fan, F., Liu, Y., Qin, W., Dore, A. J., Peng, J., Xu, W., Zhang, F., 2020. Spatio-temporal patterns of air pollution in China from 2015 to 2018 and implications for health risks. Environ. Poll., 258, 113659 . 
Kloog, I., Sorek-Hamer, M., Lyapustin, A., Coull, B., Wang, Y., Just, A. C., Schwartz, J., Broday, D. M., 2015. Estimating daily pm2. 5 and pm10 across the complex geo-climate region of israel using maiac satellite-based aod data. Atmos. Environ. 122, 409-416.

Li, Z., Fung, J. C., Lau, A. K., 2018. High spatiotemporal characterization of on-road pm2.5 concentrations in high-density urban areas using mobile monitoring. Build. Environ. 143, 196 - 205.

Lin, X., Zhang, D., 1999. Inference in generalized additive mixed modelsby using smoothing splines. J. Roy. Stat. Soc.: Series b (stat. methodol.) $61(2), 381-400$.

Liu, C, Henderson, B., Wang, D., Yang, X., Peng, Z. R., 2016. A land use regression application into assessing spatial variation of intra-urban fine particulate matter $\left(\mathrm{PM}_{2.5}\right)$ and nitrogen dioxide $\left(\mathrm{NO}_{2}\right)$ concentrations in City of Shanghai, China Sci. Tot. Environ., 5465, 607-615.

Lu, N., Liang, S., Huang, G., Qin, J., Yao, L., Wang, D., Yang, K., 2018. Hierarchical bayesian space-time estimation of monthly maximum and minimum surface air temperature. Rem. Sens. Environ. 211, 48-58.

Martín, F., Santiago, J., Kracht, O., García, L., Gerboles, M., 2015. Fairmode spatial representativeness feasibility study, forum for air quality modelling in europe. JRC Technical report EUR 27385 EN, European Commission 82 .

Martins, V., Moreno, T., Minguillon, M.C., Amato, F., de Miguel, E., Capdevila, M., Querol, X., 2015. Exposure to airborne particulate matter in the subway system, Sci. Tot. Environ., 511, 711-722.

Martins, V., Moreno, T., Mendes, L., Eleftheriadis, K., Diapouli, E., Alves, C.A., Duarte, M., de Miguel, E., Capdevila, M., Querol, X., Minguillón, M.C., 2016. Environ. Res., 146, 35-46.

Mitchell, L. E., Crosman, E. T., Jacques, A. A., Fasoli, B., Leclair-Marzolf, L., Horel, J., Bowling, D. R., Ehleringer, J. R., Lin, J. C., 2018. Monitoring of greenhouse gases and pollutants across an urban area using a light-rail public transit platform. Atmos. Environ. 187, 9-23. 
Moreno, T., Martins, V., Querol, X., Jones, T., BéruBé, K., Minguillón, M.C., Amato, F., Capdevila, M., de Miguel, E., Centelles, S., Gibbons, W., 2015. A new look at inhalable metalliferous airborne particles on rail subway platforms Sci. Tot. Environ., 505, 367-375.

Moroni, B., Castellini, S., Crocchianti, S., Cappelletti, D., Ferrero, L., Salvatori, R., Ianniello, A., Spataro, F., Esposito, G., 2014. Sources, fate and dynamics of dispersion of aerosol particles in historic cities: the case of perugia (central italy). Pro Sci. 1, 65-72.

Moroni, B., Castellini, S., Crocchianti, S., Piazzalunga, A., Fermo, P., Scardazza, F., Cappelletti, D., 2015. Ground-based measurements of long-range transported aerosol at the rural regional background site of monte martano (central italy). Atmos. Res., 155, 26-36.

Ott, W., Eliassen, R., 1973. A Survey Technique for Determining The Representativeness of Urban Air Monitoring Stations With Respect to Carbon Monoxide. J. Air Pollut. Control Assoc., 23, 685-690.

Padró-Martínez, L. T., Patton, A. P., Trull, J. B., Zamore, W., Brugge, D., Durant, J. L., 2012. Mobile monitoring of particle number concentration and other traffic-related air pollutants in a near-highway neighborhood over the course of a year. Atmos. Environ. 61, 253 - 264.

Pasquier, A., André, M., 2017. Considering criteria related to spatial variabilities for the assessment of air pollution from traffic Transport. Res. Proc. 25, 3354-3369.

Pattinson, W., Longley, I., Kingham, S., 2014. Using mobile monitoring to visualise diurnal variation of traffic pollutants across two near-highway neighbourhoods, Atmos. Environ., 94, 782-792.

Patton, A. P., Perkins, J., Zamore, W., Levy, J. I., Brugge, D., Durant, J. L., 2014. Spatial and temporal differences in traffic-related air pollution in three urban neighborhoods near an interstate highway. Atmos. Environ. 99, $309-321$.

Perrino, C., Pietrodangelo, A., Febo, A., 2011. An atmospheric stability index based on radon progeny measurements for the evaluation of primary urban pollution. Atmos. Environ. 35, 5235 - 5244. 
Peters, J., den Bossche, J. V., Reggente, M., Poppel, M. V., Baets, B. D., Theunis, J., 2014. Cyclist exposure to ufp and bc on urban routes in antwerp, belgium. Atmos. Environ., 92, $31-43$.

Petroselli, C., Crocchianti, S., Moroni, B., Castellini, S., Selvaggi, R., Nava, S., Calzolai, G., Lucarelli, F., Cappelletti, D., 2018. Disentangling the major source areas for an intense aerosol advection in the central mediterranean on the basis of potential source contribution function modeling of chemical and size distribution measurements. Atmos. Res. 204, 67-77.

Raaschou-Nielsen, O., Andersen, Z., Beelen, R., Samoli, E., Stafoggia, M., Weinmayr, G., Hoffmann, B., Fischer, P., Nieuwenhuijsen, M., Brunekreef, B., Xun, W., Katsouyanni, K., Dimakopoulou, K., Sommar, J., Forsberg, B., Modig, L., Oudin, A., Oftedal, B., Schwarze, P., Nafstad, P., Faire, U. D., Pedersen, N., Östenson, C., Fratiglioni, L., Penell, J., Korek, M., Pershagen, G., Eriksen, K., Sorensen, M., Tjonneland, A., Ellermann, T., Eeftens, M., Peeters, P., Meliefste, K., Wang, M., de Mesquita T.J. Key, B. B., de Hoogh H. Concin, K., Nagel, G., Vilier, A., Grioni, S., Krogh, V., Tsai, M., Ricceri, F., Sacerdote, C., Galassi, C., Migliore, E., Ranzi, A., Cesaroni, G., Badaloni, C., Forastiere, F., Tamayo, I., Amiano, P., Dorronsoro, M., Trichopoulou, A., Bamia, C., Vineis, P., Hoek, G., 2013. Air pollution and lung cancer incidence in 17 european cohorts: prospective analyses from the european study of cohorts for air pollution effects (escape). Lancet Onc. 14, $813-822$.

Ranalli, M. G., Rocco, G., Jona Lasinio, G., Moroni, B., Castellini, S., Crocchianti, S., Cappelletti, D., 2016. Functional exploratory data analysis for high-resolution measurements of urban particulate matter. Biometr. J., 58, $1229-1247$.

Riley, E. A., Schaal, L., Sasakura, M., Crampton, R., Gould, T. R., Hartin, K., Sheppard, L., Larson, T., Simpson, C. D., Yost, M. G., 2016. Correlations between short-term mobile monitoring and long-term passive sampler measurements of traffic-related air pollution. Atmos. Environ. 132, 229 239 .

Rizza, V., Stabile, L., Buonanno, G., Morawska, L. 2017. Variability of airborne particle metrics in an urban area. Environ.Poll. 220, 625-635. 
Ruppert, D., Wand, M. P., Carroll, R. J., 2003. Semiparametric regression. No. 12. Cambridge university press.

Sahu, S., Gelfand, A., Holland, D., 2007. High-resolution space-time ozone modeling for assessing trends. J. Am. Stat. Assoc. 102, 1221-1234.

Sahu, S. K., Yip, S., Holland, D. M., 2009. Improved space-time forecasting of next day ozone concentrations in the eastern us. Atmos. Environ. 43, 494-501.

Schwarz, G., 1978. Estimating the dimension of a model. Ann. Stat., 6, 461464.

Van Poppel, M., Peters, J., Bleux, N., 2013. Methodology for setup and data processing of mobile air quality measurements to assess the spatial variability of concentrations in urban environments, Environ. Poll., 183, 224-233.

Virgilio, G. D., Hart, M. A., Jiang, N., 2018. Meteorological controls on atmospheric particulate pollution during hazard reduction burns. Atmos. Chem. Phys. 18, 6585-6599.

von Brömssen, C., Fölster, J., Futter, M., McEwan, K., 2018. Statistical models for evaluating suspected artefacts in long-term environmental monitoring data. Environ. Monit. Assess. 190, 558.

Westerdahl, D., Fruin, S., Sax, T., Fine, P.M., Sioutas, C., 2005. Mobile platform measurements of ultrafine particles and associated pollutant concentrations on freeways and residential streets in Los Angeles, Atmos. Environ. $39,3597-3610$.

Wood, S. N., 2017. Generalized additive models: an introduction with R. Chapman and Hall/CRC.

Yu, C. H., Fan, Z., Lioy, P. J., Baptista, A., Greenberg, M., Laumbach, R. J., 2016. A novel mobile monitoring approach to characterize spatial and temporal variation in traffic-related air pollutants in an urban community. Atmos. Environ. 141, 161 - 173.

Zhang, Z., Wang, J., Hart, J. E., Laden, F., Zhao, C., Li, T., Zheng, P., Li, D., Ye, Z., Chen, K., 2018. National scale spatiotemporal land-use 
759 regression model for $\mathrm{PM}_{2.5}, \mathrm{PM}_{10}$ and $\mathrm{NO}_{2}$ concentration in china. Atmos. 760 Environ. 192, 48-54.

Zhou, Y., Levy, J. I., 2007. Factors influencing the spatial extent of mobile source air pollution impacts: a meta-analysis. BMC Public Health, 7, 8999. 
Table 1: Main air quality parameters registerd at AQ1 and AQ2 stations for the full period (2012-2015) and for the typical year (March 2013-February 2015). Standard deviations in parenthesys.

\begin{tabular}{lcccc}
\hline & \multicolumn{2}{c}{ AQ1 } & \multicolumn{2}{c}{ AQ2 } \\
\hline & $2012-2015$ & typical year & $2012-2015$ & typical year \\
$\mathrm{T}\left({ }^{\circ} \mathrm{C}\right)$ & $14.0(7.6)$ & $13.8(7.7)$ & & \\
wind speed $(\mathrm{m} / \mathrm{s})$ & $0.80(0.6)$ & $0.70(0.6)$ & $0.9(0.6)$ & $0.9(0.6)$ \\
$\mathrm{RH}(\%)$ & $75.2(12)$ & $76.3(13)$ & & \\
$\mathrm{PM}_{10}\left(\mu \mathrm{g} \mathrm{m}^{-3}\right)$ & $23.3(11)$ & $21.6(10)$ & $21.0(12)$ & $20.2(12)$ \\
$\mathrm{PM}_{2.5}\left(\mu \mathrm{g} \mathrm{m}^{-3}\right)$ & $15.9(8)$ & $14.5(8)$ & $14.3(9)$ & $13.7(9)$ \\
$\mathrm{NO}(\mathrm{ppbv})$ & $14.6(20)$ & $15.4(20)$ & $18.2(22)$ & $18.1(23)$ \\
$\mathrm{NO}_{2} / \mathrm{NOx}$ & 0.48 & 0.45 & 0.53 & 0.54 \\
$\mathrm{O}_{3}(\mathrm{ppbv})$ & $22.5(11)$ & $19.9(10)$ & $18.5(11)$ & $18.3(11)$ \\
\hline
\end{tabular}

764 
Table 2: Parameter posterior means and $95 \%$ credible intervals (95\% CI) for nitric monoxide (NO), Fine and Coarse particle concentrations. Reference day is Sunday.

\begin{tabular}{lcccccc}
\hline & \multicolumn{2}{c}{ NO } & \multicolumn{2}{c}{ Fine } & \multicolumn{2}{c}{ Coarse } \\
\hline parameter & mean & $(95 \%$ CI $)$ & mean & $(95 \%$ CI $)$ & mean & $(95 \%$ CI $)$ \\
Intercept & 1.421 & $(1.350 ; 1.490)$ & 1.551 & $(1.495 ; 1.610)$ & 0.682 & $(0.641 ; 0.722)$ \\
Mon & 0.170 & $(0.142 ; 0.198)$ & -0.006 & $(-0.021 ; 0.010)$ & -0.042 & $(-0.055 ;-0.029)$ \\
Tue & 0.192 & $(0.166 ; 0.220)$ & -0.073 & $(-0.089 ;-0.057)$ & -0.030 & $(-0.043 ;-0.017)$ \\
Wed & 0.136 & $(0.110 ; 0.163)$ & -0.092 & $(-0.107 ;-0.076)$ & -0.070 & $(-0.083 ;-0.057)$ \\
Thu & 0.112 & $(0.084 ; 0.139)$ & -0.038 & $(-0.054 ;-0.022)$ & -0.094 & $(-0.108 ;-0.080)$ \\
Fri & 0.294 & $(0.267 ; 0.322)$ & 0.066 & $(0.050 ; 0.082)$ & 0.034 & $(0.021 ; 0.047)$ \\
Sat & 0.059 & $(0.033 ; 0.087)$ & -0.032 & $(-0.048 ;-0.017)$ & -0.060 & $(-0.073 ;-0.047)$ \\
Tunnel & -0.083 & $(-0.103 ;-0.064)$ & -0.006 & $(-0.012 ; 0.001)$ & -0.001 & $(-0.010 ; 0.008)$ \\
Urban Park & -0.043 & $(-0.067 ;-0.019)$ & -0.004 & $(-0.012 ; 0.004)$ & -0.002 & $(-0.014 ; 0.009)$ \\
Station & -0.027 & $(-0.042 ;-0.013)$ & 0.007 & $(0.004 ; 0.010)$ & 0.013 & $(0.006 ; 0.019)$ \\
Temp (degC) & -0.030 & $(-0.032 ;-0.028)$ & -0.010 & $(-0.011 ;-0.009)$ & 0.005 & $(0.004 ; 0.006)$ \\
RH $(\%, \times 10)$ & -0.0047 & $(-0.0079 ;-0.0015)$ & 0.0048 & $(0.003 ; 0.006)$ & -0.0014 & $(-0.0029 ; 0.0002)$ \\
\hline$\rho$ & 0.260 & $(0.252 ; 0.268)$ & 0.872 & $(0.868 ; 0.877)$ & 0.886 & $(0.881 ; 0.890)$ \\
distance $(\mathrm{m})$ & 143 & $-;-$ & 475 & $-;-$ & 165 & $-;--$ \\
\hline
\end{tabular}




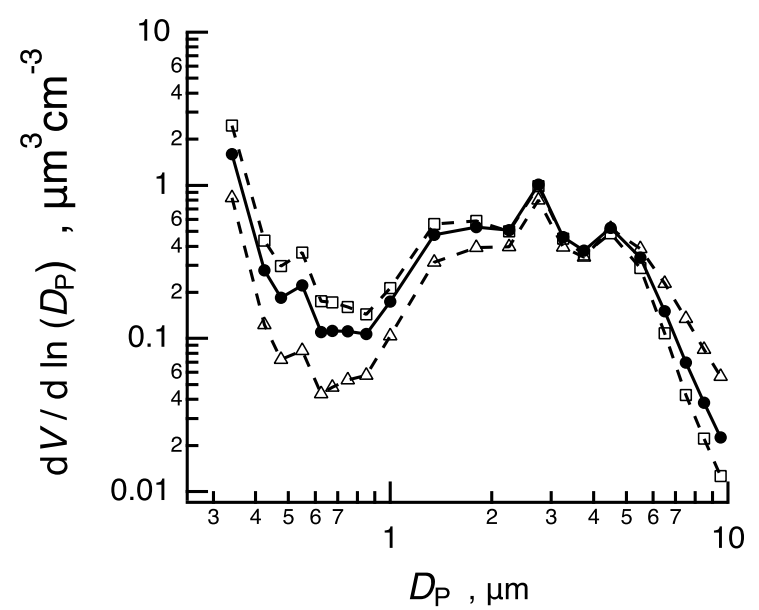

Figure 1: Mean PM volume distribution recorded in Perugia (2012-2015). The distribution is averaged over the entire MM path. Seasonal distribution are also reported for winter (open squares) and summer (open triangles). Relative standard errors are of the order of $1 \%$.
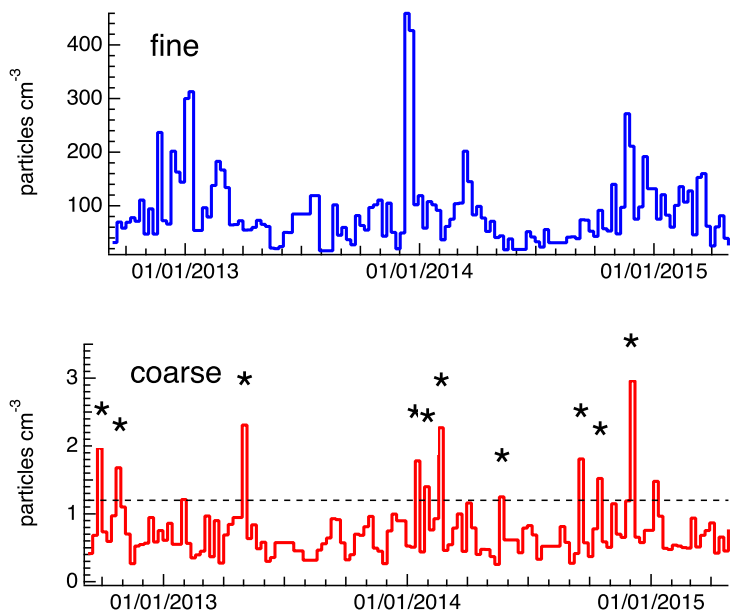

Figure 2: Weekly PM number concentration trends (2012-2015). Particles are grouped into fine (upper panel, blue curve, $0.28 \leq D_{P}<1.1 \mu \mathrm{m}$ ) and coarse (lower panel, red curve $\left.1.1 \leq D_{P}<10 . \mu \mathrm{m}\right)$ fractions. Asterisks indicate weeks of intense Saharan dust intrusion (see text). The dashed line corresponds to the dataset $90^{t h}$ percentile. 

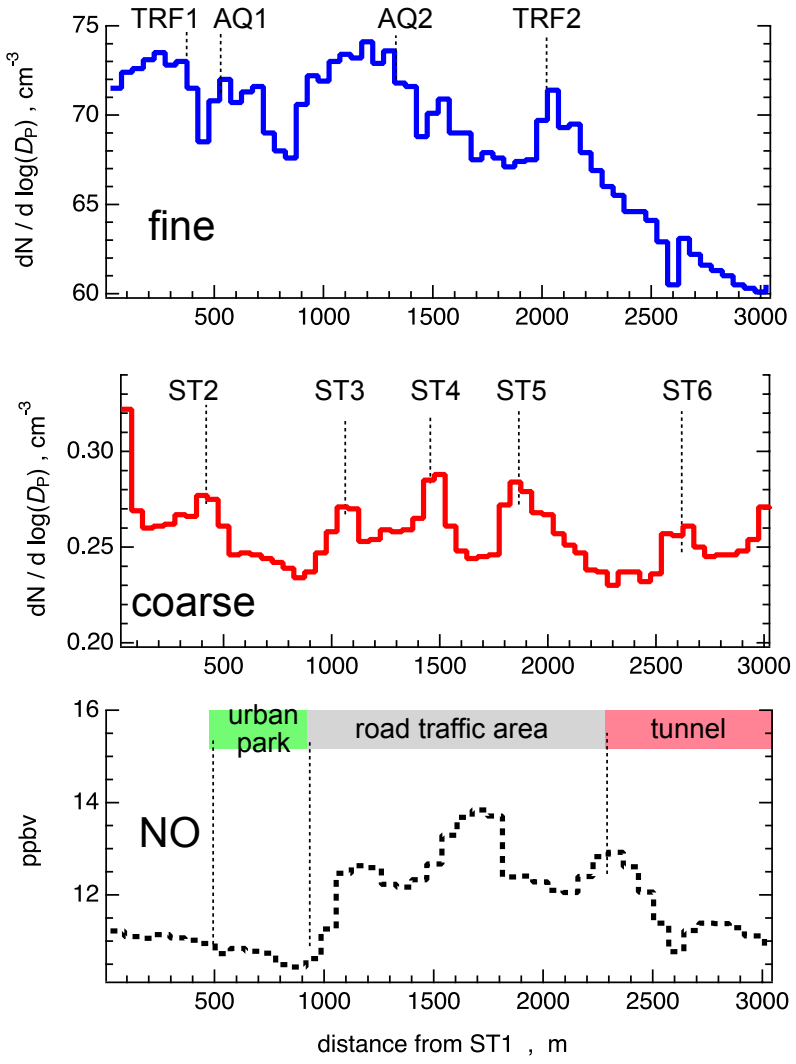

Figure 3: PM number and NO concentration trends along the MM path, as a function of the linear distance from the ST1 station. Particles are grouped into fine and coarse fractions (see Fig. 2). The indicative position of different area of the city are shown in the lower panel. The location of stations is individuated by the vertical dashed lines (terminal stations ST1 and ST7 are not shown). The location of the traffic monitoring stations TRF1 and TRF2 and air quality stations AQ1 and AQ2 is also shown. Relative standard errors are of the order of $1 \%$. 

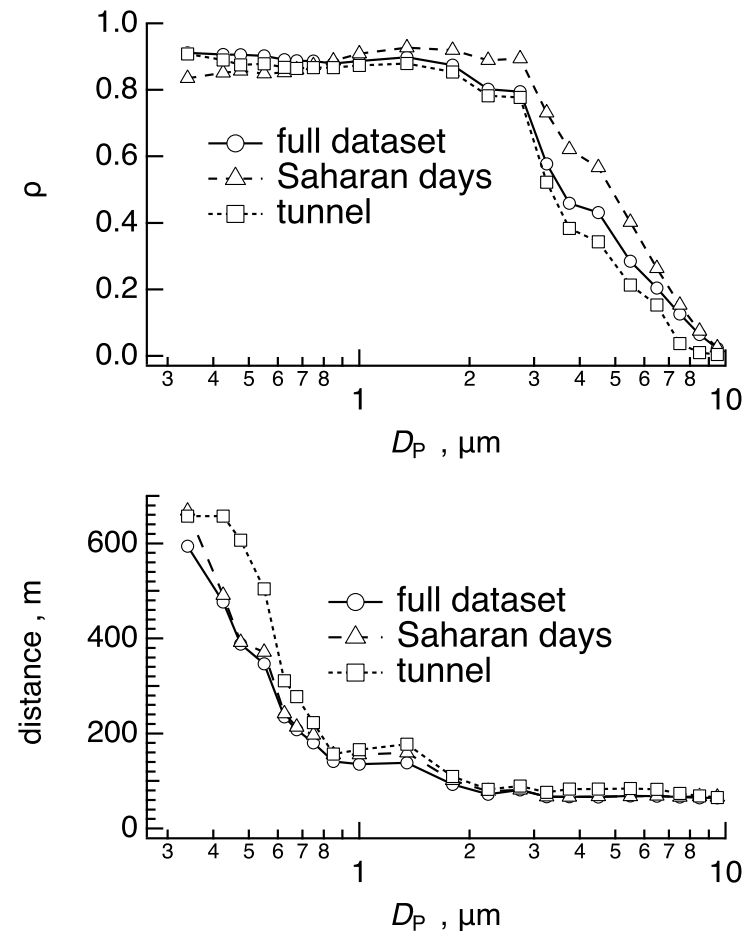

Figure 4: Temporal autocorrelation parameter $\rho$ (upper panel) and spatial correlation distance (lower panel), as a function of the particle diameter $D_{P}$. Triangles are results obtained for days of Saharan dust intrusion. Squares are results for the terminal tunnel. 


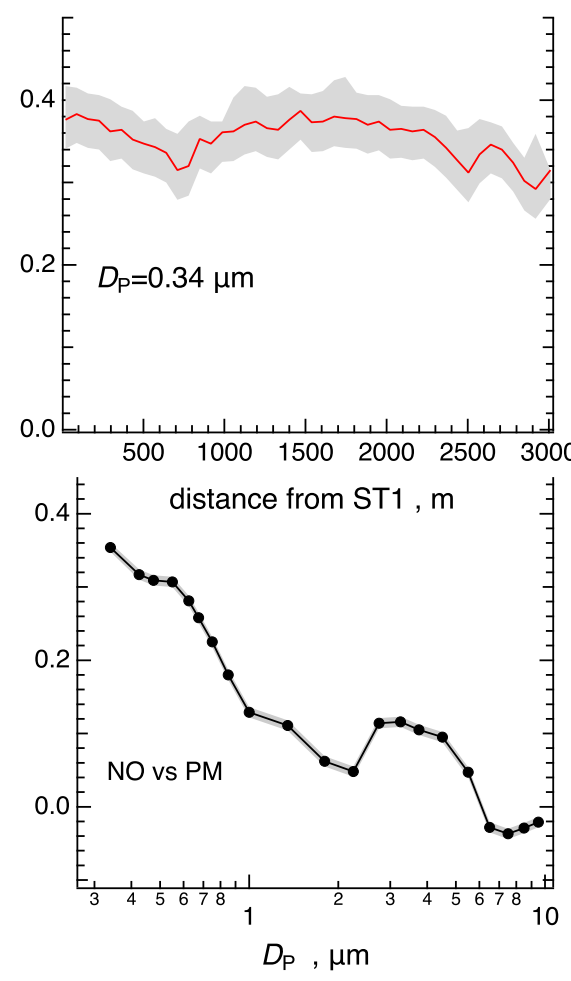

Figure 5: Upper panel: variation along the MM path of the linear correlation coefficient between NO and PM concentrations, for the smallest PM size bin $\left(D_{P}=0.34 \mu \mathrm{m}\right)$. Lower panel: linear correlation coefficient between NO and PM concentrations as a function of the particle size $D_{P}$, averaged along the entire MM path. $95 \%$ confidence intervals are also reported in gray. 


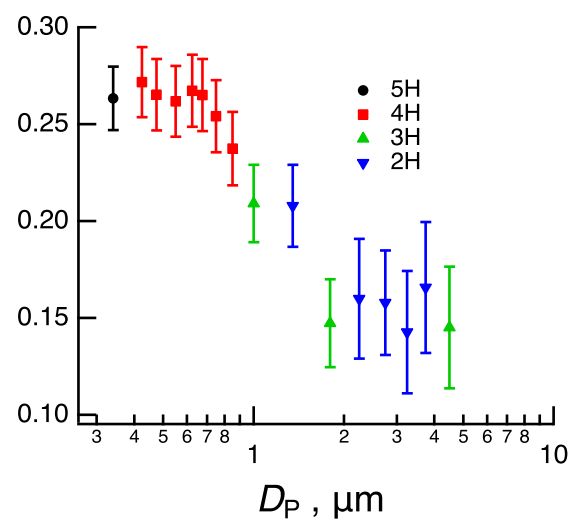

Figure 6: Estimated regression coefficient with $95 \%$ confidence for traffic-related covariate on PM number concentration, as a function of the particle diameter, $D_{P}$. Colors and symbols were used to identify the best traffic covariate for each bin (in terms of number of previous hours $H$ ). 

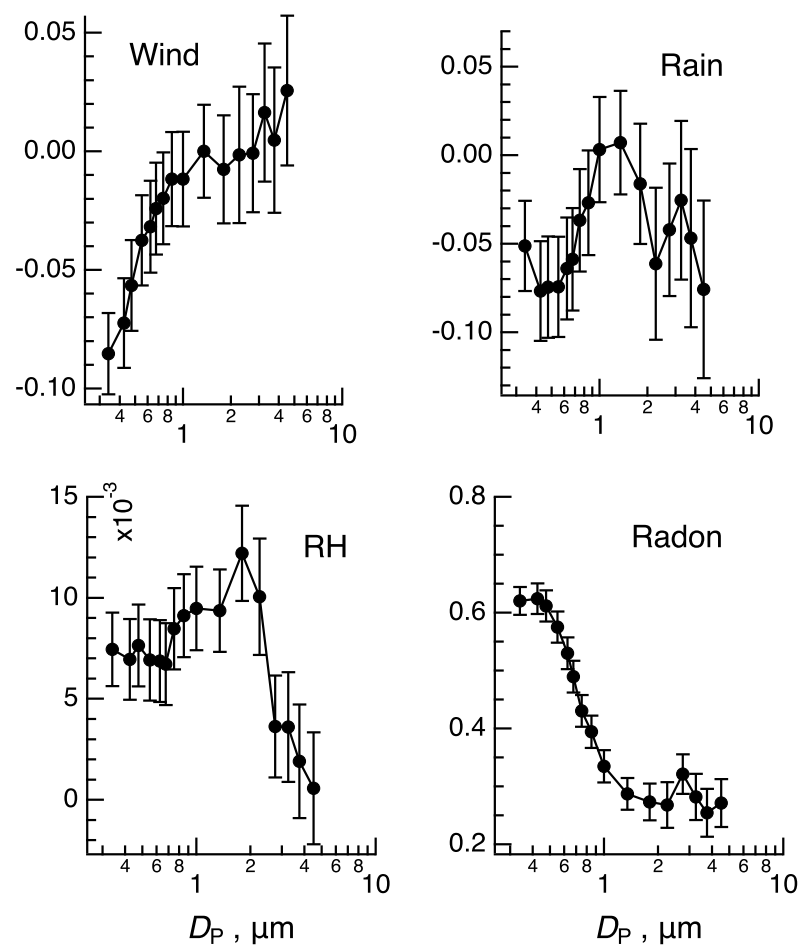

Figure 7: Estimated regression coefficient with 95\% confidence for meteorological covariates on PM number concentration, as a function of the particle diameter, $D_{P}$. 